\title{
Article
}

\section{One-step aldol condensation reaction of dimethoxymethane and methyl acetate over supported Cs/ZSM-35 zeolite catalysts}

\author{
Zhanling Ma a,b,c, Xiangang Ma b, Hongchao Liu b, Wenliang Zhu b,\#, Xinwen Guo a, Zhongmin Liu b,* \\ a State Key Laboratory of Fine Chemicals, PSU-DUT Joint Center for Energy Research, School of Chemical Engineering, Dalian University of Technology, \\ Dalian 116024, Liaoning, China \\ ${ }^{\mathrm{b}}$ National Engineering Laboratory for Methanol to Olefins, Dalian Institute of Chemical Physics, Chinese Academy of Sciences, Dalian 116023, Liaoning, \\ China \\ c University of Chinese Academy of Sciences, Beijing 100049, China
}

\section{A R T I C L E I N F O}

\section{Article history:}

Received 26 February 2018

Accepted 2 April 2018

Published 5 June 2018

\section{Keywords:}

Aldol condensation

Dimethoxymethane

Methyl acetate

Zeolite

Acidity

\begin{abstract}
A B S T R A C T
This study was performed for the development of a green and promising approach for the synthesis of methyl acrylate and acrylic acid by a one-step aldol condensation reaction of dimethoxymethane and methyl acetate over cesium oxide-supported on ZSM-35 zeolite catalysts; the effect of base sites as well as acid sites on the aldol condensation reaction was studied in detail. It was found that base sites were harmful for aldol condensation due to their failure in catalyzing the decomposition of dimethoxymethane precursor into formaldehyde, whereas the acid site was indispensable for the reaction to proceed. This reaction cannot take place without an acid site. Although acid sites in H-form of the zeolite (HZSM-35) are indispensable for the aldol condensation reaction, not all of them tend to favor this reaction. A strong acid catalyzes methanol-to-olefin-like reactions resulting in hydrocarbon byproducts, which are finally transferred to hard coke. Medium strong acids and weak acids are great candidates for the target aldol condensation reaction with high activity and selectivity. A $\gamma-\mathrm{Al}_{2} \mathrm{O}_{3}$ sample with abundant weak-strength Lewis acid sites, together with a few medium-strong-strength acid sites, performs well with a high activity and considerable stability during the synthesis of methyl acrylate and acrylic acid.
\end{abstract}

(C) 2018, Dalian Institute of Chemical Physics, Chinese Academy of Sciences. Published by Elsevier B.V. All rights reserved.

\section{Introduction}

Acrylic acid (AA) and methyl acrylate (MA), widely used for paintings, coatings, carbon fibers, and adhesives, are presently produced by the two-step oxidation of propylene [1-5]. In this process, propylene is oxidized with oxygen/air to produce acrolein followed by oxidation of acrolein to AA. After the esterification of AA with methanol, AA is converted into MA. However, this two-step process is accompanied by the over-oxidation of propylene, resulting in a low selectivity of AA, and further poses a risk of explosion due to the direct mixing of hydrocarbons with oxygen/air, which limits the widespread application of this route. Therefore, it is highly necessary to develop a novel green route for MA and AA synthesis.

The synthesis of MA and AA through the one-step aldol condensation reaction of formaldehyde with methyl acetate (MAc) has attracted substantial interest and concern from both academic and industrial communities in the past few decades because of its simplified reaction route and common feedstocks, which can be readily derived from natural gas, coal, and

\footnotetext{
* Corresponding author. Tel: +86-411-84379998; Fax: +86-411-84379038; E-mail: liuzm@dicp.ac.cn \# Corresponding author. Tel: +86-411-84379418; Fax: +86-411-84379038; E-mail: wlzhu@dicp.ac.cn DOI: 10.1016/S1872-2067(18)63069-4 | http://www.sciencedirect.com/science/journal/18722067 | Chin. J. Catal., Vol. 39, No. 6, June 2018
} 
biomass [6,7]. This reaction has been reported to be catalyzed by acids, bases, or base-acid bifunctional catalysts, among which acid-base bifunctional catalysts attract most attention owing to their good performance in aldol condensation reactions as a result of cooperation between their acid and base active sites. For example, it was reported that the yield of methyl methacrylate over supported cesium oxide catalysts was not more than $23.0 \%$ during the aldol condensation reaction of methyl propionate and formaldehyde [8,9], but the yield was doubled over cesium catalysts doped with other metals with acid-base bifunctional properties [10]. In addition, V-P oxide catalysts attract much academic attention owing to their similar acid-base bifunctional properties. Spivey et al. [11] evaluated at least 80 catalytic materials and found $V$ oxides supported on amorphous silica to be the most effective. Ai [12-17] conducted the aldol condensation reaction of propionic acid with formaldehyde over V-P-Si samples and obtained a yield of $70 \%$ at the optimum experimental conditions. Gogate et al. [18] studied the vapor phase aldol condensation reaction of formaldehyde with propionate derivatives over a series of $\mathrm{V}-\mathrm{P}-\mathrm{Si}$ catalysts of varying atomic ratios and obtained a maximum methacrylic acid yield of $56 \%$. V-P-Si catalysts also perform well in the aldol condensation reaction of formaldehyde with other carbonyl compounds, such as acetone or acetaldehyde [19-21].

The effect of the acid-base bifunctional property of $\mathrm{V}-\mathrm{P}-\mathrm{Si}$ ternary oxide catalysts was studied in the case of the aldol condensation of acetic acid or methyl acetate with formaldehyde to prepare MA and AA. Hu et al. [22] prepared V-P-Si catalysts with high acid and alkali quantities by the incipient wetness impregnation method and found that the activities of these catalysts for the conversion of formaldehyde increased with an increase in the alkali quantity, while the selectivity for acrylic acid increased with an increase in the acid quantity. This means that the acid-base properties of these catalysts play a significant role in enhancing both precursor conversion and product selectivity. Yang et al. [23] found that weak base sites were essential for aldol condensation, while weak acid sites were responsible for improvement in the selectivity of acrylic acid over a series of V-P-Si catalysts. Feng et al. [24] studied the correlation between the catalyst structure and constitution of a V-P catalyst and its performance in the aldol condensation reaction of acetic acid or methyl acetate and formaldehyde and found that catalysts containing medium-strong acid sites of high density performed much better. In our previous work on the aldol condensation reaction of formaldehyde with methyl acetate over a pure acidic $\mathrm{H}$-form of a zeolite to produce MA and $\mathrm{AA}$, we reported an optimum yield as high as $61.1 \%$ [25]. It seems that base sites as well as acid sites are greatly helpful in catalyzing aldol condensation reactions.

Herein, we prepared a series of zeolites supported by varying weight percentages of cesium oxide by an incipient wetness impregnation method in order to study the effect of base sites or acid sites on the performance of the aldol condensation reaction. Dimethoxymethane (DMM) was used as the source of formaldehyde. The textural and acid-base properties of these samples were characterized in detail and their relationship with the performance of the aldol condensation reaction was illustrated.

\section{Experimental}

\subsection{Catalyst preparation}

Zeolites (ZSM-35) and $\gamma-\mathrm{Al}_{2} \mathrm{O}_{3}$ were purchased from the Shanghai Zhuoyue Chemical Limited Company, China. The zeolite sample was converted into a H-form of HZSM-35 before use by conducting ion exchange thrice at $80^{\circ} \mathrm{C}$ for $6 \mathrm{~h}$ in $1 \mathrm{~mol} / \mathrm{L}$ $\mathrm{NH}_{4} \mathrm{NO}_{3}$, followed by washing with deionized water, drying at $100{ }^{\circ} \mathrm{C}$ overnight, and calcination at $550{ }^{\circ} \mathrm{C}$ for $4 \mathrm{~h}$.

To synthesize the zeolite-supported alkaline metal cesium oxide catalysts, the HZSM-35 zeolite precursor was impregnated with an aqueous solution containing varying amounts of $\mathrm{Cs}_{2} \mathrm{CO}_{3}$. The mixture was heated with stirring at $50{ }^{\circ} \mathrm{C}$ for at least $5 \mathrm{~h}$ until a paste-like material is formed and then dried in an oven. The dried sample was calcined in flowing air at $500{ }^{\circ} \mathrm{C}$ for $4 \mathrm{~h}$. The sample was denoted as $\mathrm{Z}-\mathrm{Cs}-\mathrm{X}$, where $\mathrm{Z}$ denotes zeolite and $X$ refers to the weight percentage of the alkaline metal. Before use, the sample powder was pressed and sieved to obtain particles in the size range of $20-40$ mesh. We also prepared silica-supported alkaline metal oxide samples using a similar method.

\subsection{Characterization}

The crystallinities of the samples were characterized by a PANalytical X'Pert PRO X-ray diffraction (XRD) instrument with $\mathrm{Cu} K_{\alpha}$ radiation $(\lambda=1.51059 \AA)$ at $40 \mathrm{kV}$ and $40 \mathrm{~mA}$.

The total surface area was calculated according to the Brunauer-Emmett-Teller (BET) equation. The micropore volumes and micropore surface areas were evaluated using the $t$-plot method. The mesopore volumes were calculated using the Barrett-Joyner-Halenda (BJH) method.

The bulk acidity of the zeolite was determined by the temperature-programmed desorption of ammonia ( $\mathrm{NH}_{3}-\mathrm{TPD}$ ) on a Micromeritics AutoChem 2920 instrument. The sample $(0.2 \mathrm{~g})$ was loaded in a U-shaped microreactor and preheated at 550 ${ }^{\circ} \mathrm{C}$ for $0.5 \mathrm{~h}$ in a helium atmosphere. After cooling to $100{ }^{\circ} \mathrm{C}$, the sample was saturated with ammonia, followed by purging with helium to remove physically adsorbed ammonia molecules. Ammonia desorption was conducted in a flowing helium atmosphere $(30 \mathrm{~mL} / \mathrm{min})$ by heating from 100 to $650{ }^{\circ} \mathrm{C}$ at a rate of $10{ }^{\circ} \mathrm{C} / \mathrm{min}$; desorption was analyzed using a thermal conductivity detector (TCD).

Fourier transform infrared (FT-IR) spectroscopy was conducted at a spectral resolution of $4 \mathrm{~cm}^{-1}$ on a Bruker Tensor 27 FT-IR spectrophotometer equipped with a mercury-cadmium-telluride (MCT) detector, which was sensitive to -OH group vibrations. The sample was pressed into a self-supporting disk with a diameter of $13 \mathrm{~mm}$. The disk was then put in a quartz cell connected to a vacuum system, sealed with $\mathrm{CaF}_{2}$ windows, and then heated up to $450{ }^{\circ} \mathrm{C}$ for at least 4 $\mathrm{h}$ to remove any retained water before collecting the spectra. Pyridine adsorption was analyzed by exposing the preheated 
disk to a pyridine vapor at room temperature. All the spectra were collected at the room temperature.

Thermogravimetric analysis (TGA) was conducted on a thermogravimetric analyzer (Q600 SDT/Omnistar). About 10 mg of the deactivated sample was placed in an $\mathrm{Al}_{2} \mathrm{O}_{3}$ crucible and then heated from room temperature to $800{ }^{\circ} \mathrm{C}$ at a rate of $10^{\circ} \mathrm{C} / \mathrm{min}$ with a purging air flow of $100 \mathrm{~mL} / \mathrm{min}$.

\subsection{Catalytic test}

The aldol condensation reaction of DMM and MAc was carried out at $350{ }^{\circ} \mathrm{C}$ with $0.5 \mathrm{~g}$ of the sample (20-40 mesh) on a fixed-bed reactor. The system pressure was set at $3 \mathrm{MPa}$. DMM and MAc precursors in two separate stainless steel tubes held at $20{ }^{\circ} \mathrm{C}$ were bubbled into the reaction tube using an $\mathrm{N}_{2}$ flow (30 $\mathrm{mL} / \mathrm{min}$ ). The obtained products were analyzed by an online gas chromatograph (GC) equipped with a flame ionization detector (FID) connected to a FFAP capillary column. The conversion of DMM to MAc was defined in terms of the molar ratio of consumed precursor to the feed. The yield was calculated as (moles of MA and AA)/(moles of MAc fed).

\section{Results and discussion}

\subsection{Characterization of zeolite samples with varying weight percentages of cesium}

As shown in Fig. 1, HZSM-35 exhibits a typical crystalline ferrierite (FER) framework with clear diffraction peaks at $9.2^{\circ}$, $25.2^{\circ}$, and $25.7^{\circ}$. The morphology of the zeolite, as characterized by scanning electron microscopy (SEM) (Fig. S1), indicates typical flake-packing. No new diffraction peaks appear after the impregnation of cesium oxide, indicating that no fused cesium oxide phase exists in the prepared samples.

The nitrogen adsorption-desorption isotherms of the samples are shown in Fig. 2 and their textual properties are listed in Table 1. HZSM-35 zeolite exhibits an isotherm typical of a

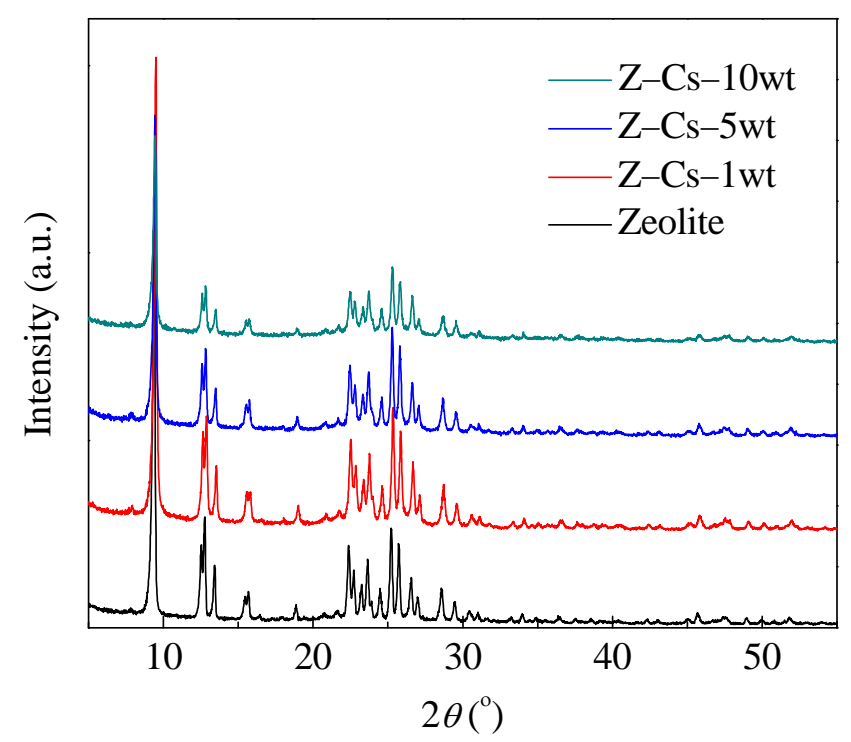

Fig. 1. XRD patterns of HZSM-35 zeolite supported by different weight percentages of cesium.

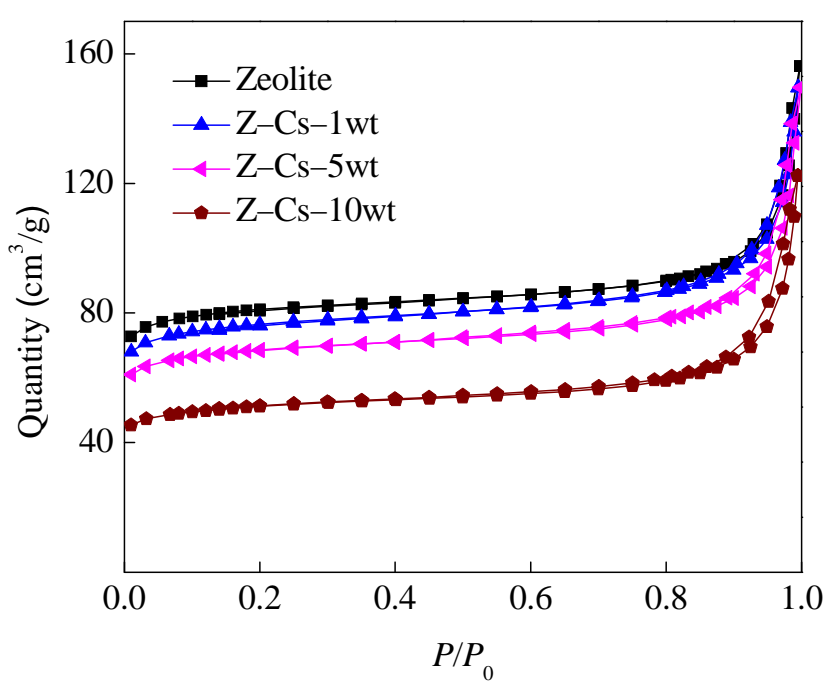

Fig. 2. Nitrogen adsorption-desorption isotherms of ZSM-35 zeolites with different weight percentages of cesium.

microporous material with a weak hysteretic loop due to the presence of inter-crystal mesopores. The BET surface area changes slightly from 262 to $258 \mathrm{~m}^{2} / \mathrm{g}$ when 1 wt $\%$ cesium was used as the support. Further, there occurs a small decrease in the micropore volume from 0.105 to $0.100 \mathrm{~cm}^{3} / \mathrm{g}$, indicating that the cesium oxide support is distributed uniformly on the zeolite surface without greatly altering its textural properties. The BET surface area decreases from 262 to $231 \mathrm{~m}^{2} / \mathrm{g}$ at a cesium weight percentage of $5 \mathrm{wt} \%$, while the micropore volume decreases from 0.105 to $0.086 \mathrm{~cm}^{3} / \mathrm{g}$ although the external surface does not decrease much (from 47 to $45 \mathrm{~m}^{2} / \mathrm{g}$ ). Micropore blockage becomes more severe with a decrease in the micropore volume from 0.105 to $0.063 \mathrm{~cm}^{3} / \mathrm{g}$ at a cesium weight percentage of $10 \mathrm{wt} \%$; this is accompanied by reductions in the BET surface area (from 262 to $173 \mathrm{~m}^{2} / \mathrm{g}$ ) and the external surface area (from 47 to $38 \mathrm{~m}^{2} / \mathrm{g}$ ). This suggests that a cesium weight percentage greater than $5 \mathrm{wt} \%$ is excessive for supporting the zeolite and would cause a severe blockage of the sample's textural properties. This is especially true in the case of micropores.

The results of $\mathrm{NH}_{3}$-TPD curves of samples with different weight percentages of cesium are shown in Fig. 3. In the case of the HZSM-35 zeolite, two typical desorption peaks of ammonia are observed at 169 and $405{ }^{\circ} \mathrm{C}$, suggesting that two types of acid sites, including weak and strong ones, are distributed in the H-form of the zeolite. However, the number of acid sites, especially the strong ones, experiences a sharp decrease after impregnation with $1 \mathrm{wt} \%$ cesium, which indicates that a large

Table 1

Textural properties of samples with different cesium weight percentages.

\begin{tabular}{lccccc}
\hline Sample & $A_{\text {BET }}\left(\mathrm{m}^{2} / \mathrm{g}\right)$ & $\begin{array}{c}A_{\text {Ext-BET }} \\
\left(\mathrm{m}^{2} / \mathrm{g}\right)\end{array}$ & $\begin{array}{c}V_{\text {micro }} \\
\left(\mathrm{cm}^{3} / \mathrm{g}\right)\end{array}$ & $\begin{array}{c}V_{\text {meso }} \\
\left(\mathrm{cm}^{3} / \mathrm{g}\right)\end{array}$ & $\begin{array}{c}V_{\text {total }} \\
\left(\mathrm{cm}^{3} / \mathrm{g}\right)\end{array}$ \\
\hline Zeolite & 262 & 47 & 0.105 & 0.075 & 0.180 \\
Z-Cs-1wt & 258 & 50 & 0.100 & 0.077 & 0.177 \\
Z-Cs-5wt & 231 & 45 & 0.086 & 0.078 & 0.164 \\
Z-Cs-10wt & 173 & 38 & 0.063 & 0.072 & 0.135 \\
\hline
\end{tabular}




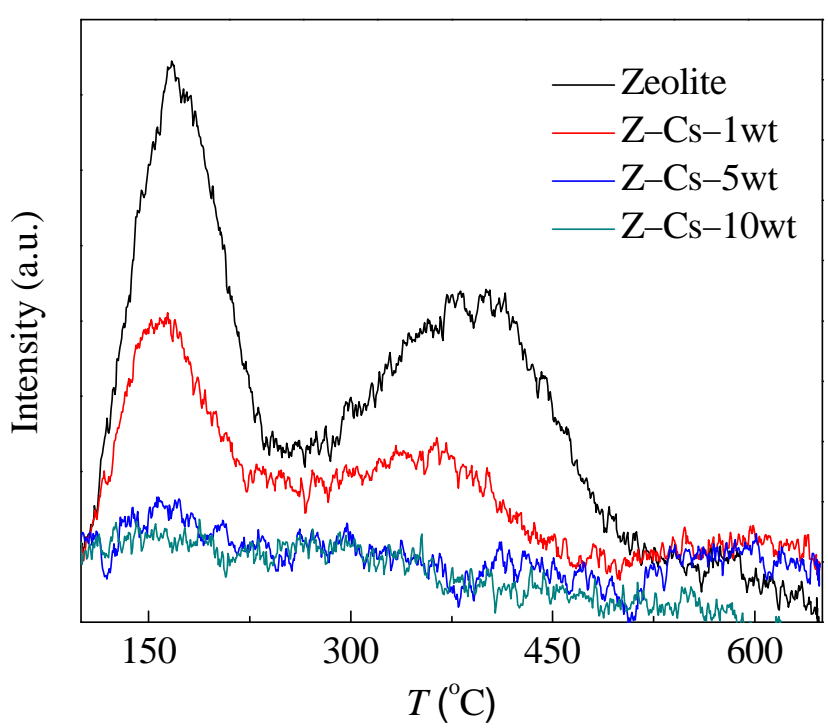

Fig. 3. Acidic properties of zeolites supported by varying weight percentages of cesium, as characterized by $\mathrm{NH}_{3}$-TPD.

proportion of the acid sites is covered by alkaline metal oxides. If the weight percentage of cesium increases to $5 \mathrm{wt} \%$, or even $10 \mathrm{wt} \%$, no peaks corresponding to ammonia desorption could be detected at either low temperatures or high temperatures, which suggests that no acidic sites exist on these two samples. It also means that there are no acid sites available for the aldol condensation reaction. We propose that these acidic sites are covered by cesium oxide after taking into account the fact that most of the pores are blocked at such high weight percentages of cesium, as described in Table 1.

\subsection{Effect of base sites on the aldol condensation of DMM and $M A C$}

DMM decomposes readily over acidic zeolite catalyst with a conversion of $100 \%$, as depicted in Fig. 4 . Its conversion does

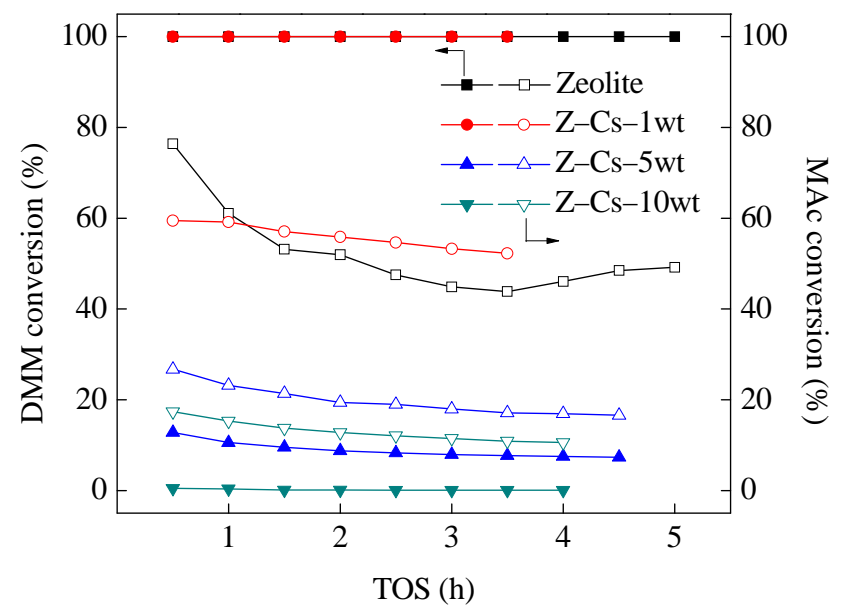

Fig. 4. Effect of cesium weight percentage on DMM and MAc conversion over zeolite supports. Cesium weight percentage was based on that of cesium element; Zeolite refers to $\mathrm{HZSM}-35, \mathrm{SiO}_{2} / \mathrm{Al}_{2} \mathrm{O}_{3}=79$, reaction temperature of $350{ }^{\circ} \mathrm{C}$, system pressure of $3 \mathrm{MPa}$ with $\mathrm{N}_{2}$ equilibrium gas, $n_{\mathrm{DMM}} / n_{\mathrm{MAc}}=2 / 1$. The saturated vapor pressures of DMM and MAc were 43.3 and $23.0 \mathrm{kPa}$, respectively. not change (still 100\%) with $1 \mathrm{wt} \%$ cesium as the support. However, it reduces to about $10 \%$ with $\mathrm{Z}-\mathrm{Cs}-5 \mathrm{wt}$ and even becomes zero in the case of Z-Cs-10wt. These results make it obvious that cesium oxide supports are harmful to DMM decomposition. This is also true for MAc precursors, whose conversion drops to $20 \%$ at a cesium weight percentage of more than $5 \mathrm{wt} \%$. Considering the fact that the alkalinity of the samples is greatly enhanced by the introduction of cesium oxide, we suggest that alkalinity is not helpful in enhancing either DMM or MAc conversion.

Conversion of either DMM or MAc on the ZSM-35 zeolite is not adversely affected by the Z-Cs-1wt sample. We know that a large number of acid sites in the Z-Cs-1wt sample are covered by the cesium oxide support, as illustrated in Fig. 3, resulting in an obvious decrease in the strengths of the ammonia desorption peaks at both low and high temperatures. This means that these acidic sites covered by cesium oxide are not necessary for the conversion of DMM and MAc. The remaining acid sites in $\mathrm{Z}-\mathrm{Cs}-1 \mathrm{wt}$ are enough to trigger the conversion of the precursor. However, if the remaining acid sites of the sample are covered, as in the case of $5 \mathrm{wt} \%$ cesium or even $10 \mathrm{wt} \%$ cesium, DMM and MAc conversion falls sharply, as shown in Fig. 4, which suggests that acidity is indispensable for the conversion of precursors in an aldol condensation reaction. But not all the acids in the HZSM-35 zeolite tend to favor aldol condensation. For instance, an obvious initial period of about $2 \mathrm{~h}$ is observed in the HZSM-35 zeolite, as shown in Fig. 4, during which the incipient conversion of MAc at TOS $=0.5 \mathrm{~h}$ is $78 \%$ and then falls to $50 \%$ rapidly. A large amount of coke is quickly formed in this period (first $2 \mathrm{~h}$ ), as shown in Fig. S2. This initial period disappeared when ZSM-35 was supported with varying weight percentages of cesium. Taking into account the fact that a large number of strong acid sites in ZSM-35 zeolite are covered by the supporting cesium oxide, we propose that strong acids in the $\mathrm{H}$-form of the zeolite cause deactivation.

The effect of added cesium oxide on the yield of MA and AA is shown in Fig. 5. In the initial period (first $2 \mathrm{~h}$ ), the yield of MA and AA with the HZSM-35 zeolite is very low, whereas a large quantity of hydrocarbon byproducts are produced due to the unavoidable methanol-to-olefin-like process at such high reaction temperatures. This period disappears immediately if zeolites are supported with cesium oxide, which in turn proves that an excess of strong acids in the HZSM-35 zeolite contributes mainly to by-reactions. Alkalinity prohibits the by-reactions caused by strong acids in the HZSM-35 zeolite. Similarly, alkalinity limits the production of MA and AA. For instance, the yield of MA and AA with the Z-Cs-1wt sample is lower than that of the HZSM-35 zeolite in the same reaction time, as shown in Fig. 5. The yield further drops from $28 \%$ in the HZSM-35 zeolite to just 3\% in Z-Cs-5wt and even to zero in Z-Cs-10wt, indicating that the supporting cesium oxide does harm rather than good in the aldol condensation reaction of DMM and MAc to produce MA and AA.

Our results show that cooperation between bases and acids is not helpful for the aldol condensation reaction; this observation is inconsistent with the conclusion of published papers, which reported that a combination of base and acid enhanced 


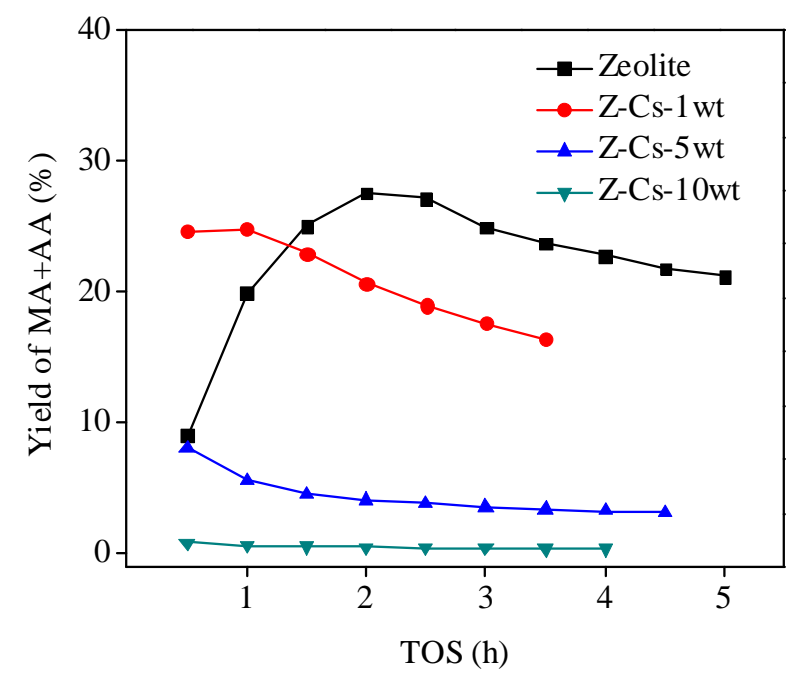

Fig. 5. Variation in MA and AA yield with reaction time over zeolites supported with different weight percentages of cesium. Zeolite: HZSM-35, $\mathrm{SiO}_{2} / \mathrm{Al}_{2} \mathrm{O}_{3}=79,350{ }^{\circ} \mathrm{C}, 3 \mathrm{MPa}$ with $\mathrm{N}_{2}$ equilibrium gas, and $n_{\mathrm{DMM}} / n_{\mathrm{MAc}}=2 / 1$. The saturated vapor pressures of DMM and MAc were 43.3 and $23.0 \mathrm{kPa}$, respectively.

the aldol condensation reaction. To analyze this discrepancy, we performed the aldol condensation of DMM and MAc over pure alkaline metal oxide catalysts, such as $\mathrm{Na}_{2} \mathrm{O}, \mathrm{K}_{2} \mathrm{O}$, and $\mathrm{Cs}_{2} \mathrm{O}$ supported on non-acidic silica prepared by a traditional wetness impregnation method, as shown in Table S1. Surprisingly, the DMM precursor hardly decomposed over these pure alkaline metal oxide catalysts and could not provide enough formaldehyde to ensure the occurrence of aldol condensation with the MAc precursor. On the contrary, DMM decomposes immediately into formaldehyde upon contact with acidic catalysts, for instance the $\mathrm{H}$-form of the zeolite, whose mass signal $(\mathrm{m} / \mathrm{z}=$ 29 ) is clearly recorded by mass spectrometry (MS), as illus- trated in Fig. S3. This fact shows that acidic sites are indispensable for the aldol condensation reaction of DMM and MAc to produce acrylic acid and methyl acrylate.

Now, it is clear that acidic sites are essential to trigger the aldol condensation reaction of DMM and MAc. Without acidic sites, this reaction would not occur. However, a strong acid contributes mainly to the by-reactions rather than the aldol condensation reaction. It seems that medium or weak acids are favorable for this reaction. Therefore, a type of $\gamma-\mathrm{Al}_{2} \mathrm{O}_{3}$ with abundant weak acid sites, together with a few medium-strong acid sites, was applied as a catalyst to verify this hypothesis.

\subsection{Efficiency of $\gamma-\mathrm{Al}_{2} \mathrm{O}_{3}$ in the aldol condensation reaction}

The $\gamma-\mathrm{Al}_{2} \mathrm{O}_{3}$ sample consists of $\mathrm{AlO}_{6}$ octahedra and $\mathrm{AlO}_{4}$ tetrahedra with a slightly tetragonally distorted face-centered cubic lattice structure. Its Lewis acidity is generally derived from the coordinatively unsaturated aluminum ions [26,27]. In this study, the acidic properties of $\gamma-\mathrm{Al}_{2} \mathrm{O}_{3}$ are studied by FT-IR characterization using pyridine as the probe molecule, as shown in Fig. 6. Three negative peaks at 3733, 3677, and 3600 $\mathrm{cm}^{-1}$ appear in the $\mathrm{OH}$ region with a small shoulder peak at around $3751 \mathrm{~cm}^{-1}$ upon the adsorption of pyridine vapor at room temperature. The peak at $3600 \mathrm{~cm}^{-1}$ disappears after desorption under vacuum for $30 \mathrm{~min}$ at $150{ }^{\circ} \mathrm{C}$ followed by the disappearance of the peaks at 1611, 1591, and $1443 \mathrm{~cm}^{-1}$, which are bands typical of physically absorbed pyridine, but one typical band at $1452 \mathrm{~cm}^{-1}$ of pyridine absorbed on Lewis acids can still be observed after desorption [28-31]. The three bands at 1624,1617 , and $1579 \mathrm{~cm}^{-1}$ are assigned to three types of Lewis acid sites of five, four, and three-coordinate $\mathrm{Al}^{3+}$ ions, respectively. By integrating the peak at $1452 \mathrm{~cm}^{-1}$, which stands for the interaction of pyridine with the total Lewis acids available, we can calculate that the total acid amount of the

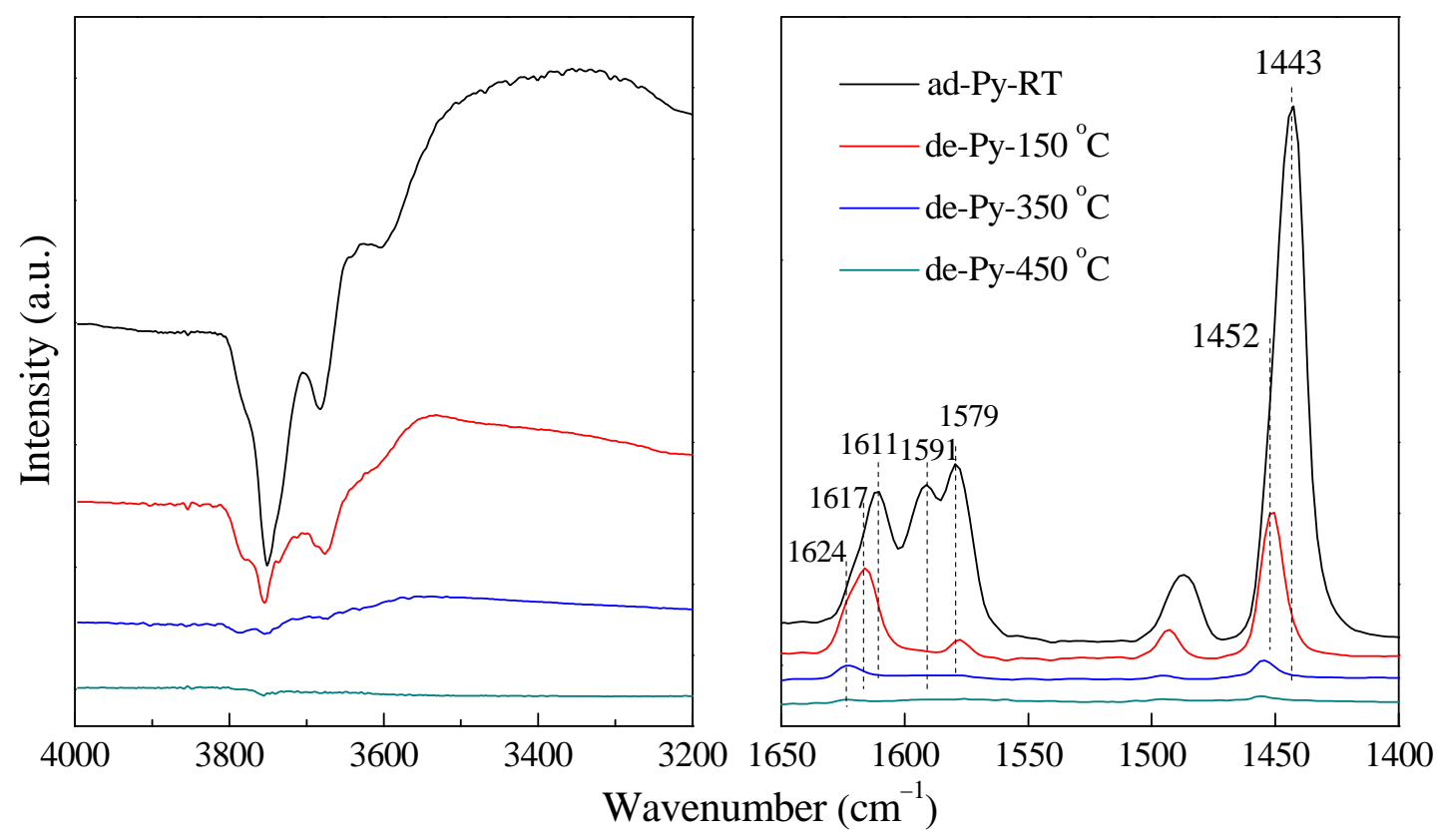

Fig. 6. FT-IR spectra of the $\gamma-\mathrm{Al}_{2} \mathrm{O}_{3}$ sample with pyridine as a probe molecule. All the above spectra detracted from that of the pure $\gamma$ - $\mathrm{Al}_{2} \mathrm{O}_{3}$ sample. 
$\gamma-\mathrm{Al}_{2} \mathrm{O}_{3}$ sample is $0.14 \mathrm{mmol} / \mathrm{g}$. The strength of the peak at $1452 \mathrm{~cm}^{-1}$ decreases greatly after desorption at $350{ }^{\circ} \mathrm{C}$ for 30 min with an acid amount of $0.02 \mathrm{mmol} / \mathrm{g}$ and even disappears at $450{ }^{\circ} \mathrm{C}$. At such high desorption temperatures, only interactions between pyridine with medium-strong and strong Lewis acids could be detected in the FT-IR spectrum. However, we observed one small absorption peak in the $\gamma-\mathrm{Al}_{2} \mathrm{O}_{3}$ sample at such high temperatures. It means that weak Lewis acids, rather than strong acids, exist predominantly in the $\gamma-\mathrm{Al}_{2} \mathrm{O}_{3}$ sample together with a small quantity of medium-strong Lewis acids. $\mathrm{NH}_{3}$-TPD results of the $\gamma-\mathrm{Al}_{2} \mathrm{O}_{3}$ sample, as shown in Fig. S4, indicated an obvious desorption peak of weak-strength acids at a low temperature of $200{ }^{\circ} \mathrm{C}$, which supported our hypothesis.

The aldol condensation reaction of DMM and MAc was conducted over the weak Lewis acidic sample $\left(\gamma-\mathrm{Al}_{2} \mathrm{O}_{3}\right)$ to evaluate whether the aldol condensation reaction can be triggered. The reaction performance over the $\gamma-\mathrm{Al}_{2} \mathrm{O}_{3}$ sample is depicted in Fig. 7. DMM is completely converted with a conversion of $100 \%$, indicating that such a weak acid is capable of catalyzing the decomposition of DMM into formaldehyde. Similarly, MAc conversion is very close to that obtained with HZSM-35. But this process proceeds much more smoothly without an obvious initial period. It is evident that the $\gamma-\mathrm{Al}_{2} \mathrm{O}_{3}$ sample is capable of converting both DMM and MAc precursors to produce MA and AA. The yield of MA and AA is $\sim 15 \%$ over the $\gamma-\mathrm{Al}_{2} \mathrm{O}_{3}$ sample. Though the yield is lower than that on HZSM-35 zeolite, the products obtained are more stable with a shorter initial period. To exclude systematic errors, we conducted the experiment once again at the same reaction conditions (blue line in Fig. 7) and achieved an excellent repeatability. Therefore, it is clear that a weak Lewis acid is enough to trigger the aldol condensation reaction of DMM and MAc to produce MA and AA with both good activity and stability.

A comparison between the aldol condensation reaction performances of the $\gamma-\mathrm{Al}_{2} \mathrm{O}_{3}$ sample and HZSM-35 zeolite is depicted in Fig. 8. DMM decomposes readily with both catalysts with $100 \%$ conversion, which proves that an acid is necessary for DMM decomposition. In the case of the MAc precursor, it

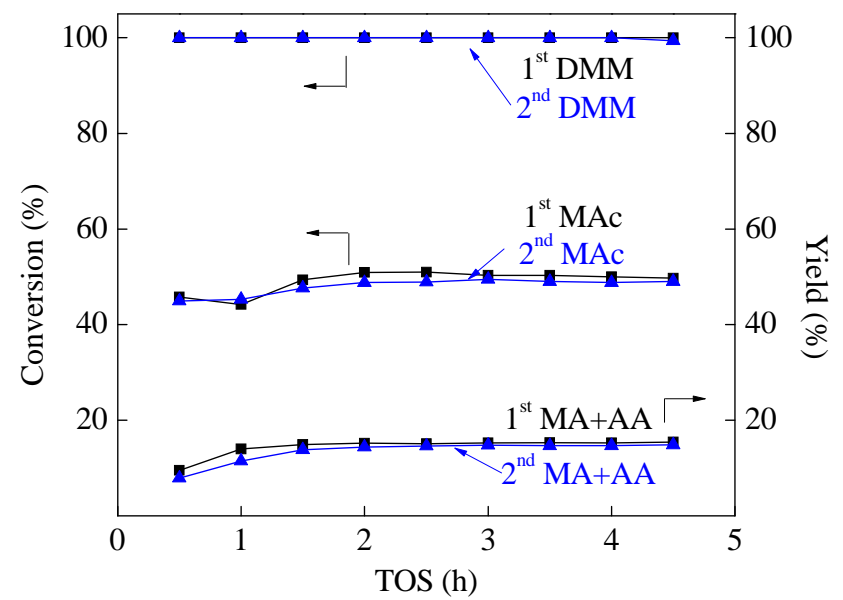

Fig. 7. Aldol condensation reaction performance over the $\gamma-\mathrm{Al}_{2} \mathrm{O}_{3}$ sample with a good repeatability. Reaction temperature of $350{ }^{\circ} \mathrm{C}, 3 \mathrm{MPa}$ with $\mathrm{N}_{2}$ as the equilibrium gas, the saturated pressures of DMM and MAc were 43.3 and $23.0 \mathrm{kPa}$, respectively, GHSV $=7.2 \mathrm{~L} \mathrm{~g}^{-1} \mathrm{~h}^{-1}$.

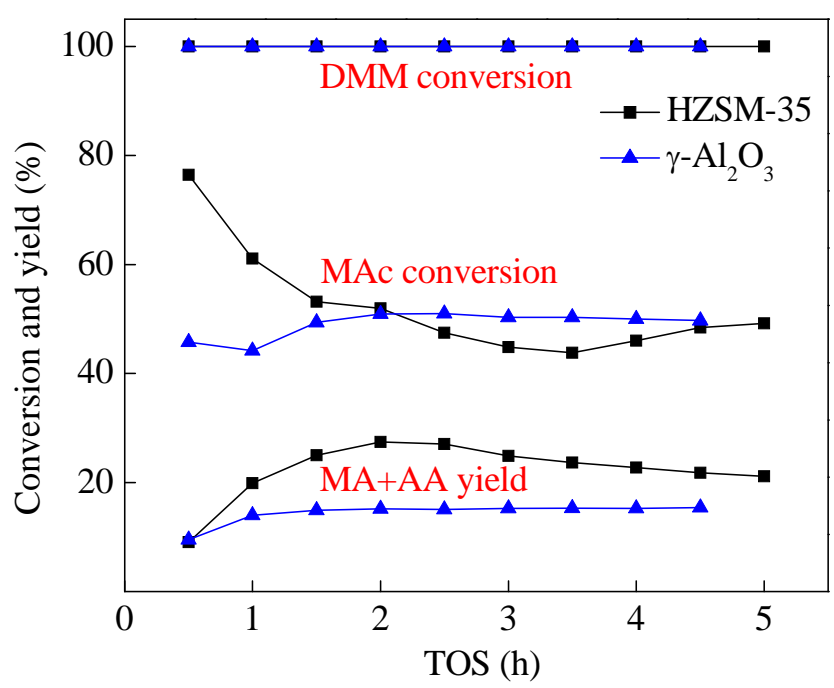

Fig. 8. Comparison of the aldol condensation reaction performances of $\gamma-\mathrm{Al}_{2} \mathrm{O}_{3}$ and HZSM-35. Reaction conditions: $350{ }^{\circ} \mathrm{C}$ and $3 \mathrm{MPa}$ with $\mathrm{N}_{2}$ as the equilibrium gas; The saturated pressures of DMM and MAc were 43.3 and $23.0 \mathrm{kPa}$, respectively, GHSV $=7.2 \mathrm{~L} \mathrm{~g}^{-1} \mathrm{~h}^{-1}$.

can be converted much more smoothly with $\gamma-\mathrm{Al}_{2} \mathrm{O}_{3}$ without significant fluctuations than with the HZSM-35 zeolite. For example, the initial conversion of MAc in HZSM-35 zeolite is very high and then falls fast in the first $2 \mathrm{~h}$. The initial high conversion of MAc is attributed to the severe MTO-like reaction catalyzed by strong Brönsted acids, as described in Fig. S5. This by-reaction is mildly catalyzed by the weak Lewis acid of the $\gamma-\mathrm{Al}_{2} \mathrm{O}_{3}$ sample with a much shorter initial period. The yield of MA and AA with the HZSM-35 zeolite is almost double of that obtained with the $\gamma-\mathrm{Al}_{2} \mathrm{O}_{3}$ sample, indicating that a cooperation between strong acids and weak acids is helpful for aldol condensation reactions.

The TGA curves and first derivatives corresponding to coked $\gamma-\mathrm{Al}_{2} \mathrm{O}_{3}$ and deactivated HZSM-35 zeolite are shown in Fig. 9. The amount of coke in $\gamma-\mathrm{Al}_{2} \mathrm{O}_{3}$ was $8.3 \mathrm{wt} \%$, which is larger than that of HZSM-35 zeolite (6.9 wt\%). However, the deactivation of HZSM-35 zeolite is much more severe. For example, the consumption temperature of coke of HZSM-35 was

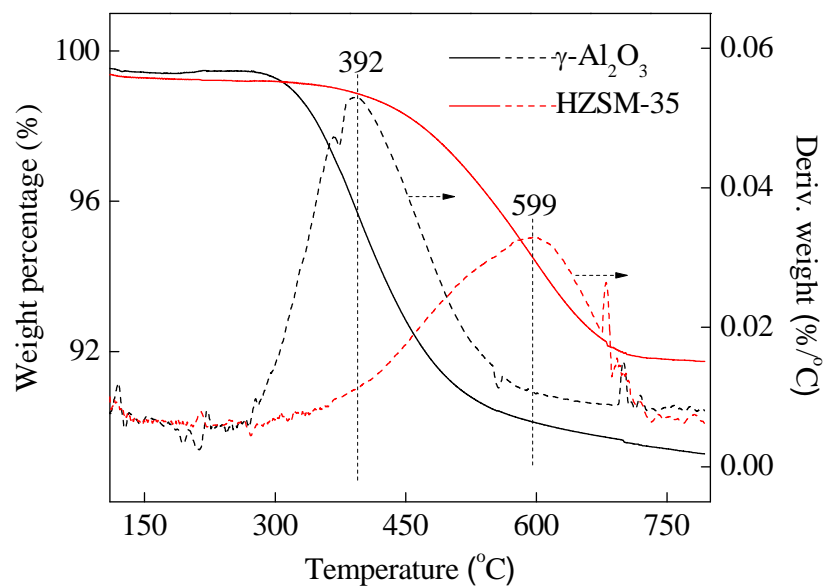

Fig. 9. The TGA curves (the solid line) and derivatives (the dotted line) of a coked $\gamma-\mathrm{Al}_{2} \mathrm{O}_{3}$ sample and deactivated HZSM-35 zeolite after $6 \mathrm{~h}$ of reaction in air. 
$599^{\circ} \mathrm{C}$, which is higher than that of the $\gamma-\mathrm{Al}_{2} \mathrm{O}_{3}$ sample $\left(392^{\circ} \mathrm{C}\right)$. Deactivation in HZSM-35 zeolite is violent with hard coke. Unlike the $\gamma-\mathrm{Al}_{2} \mathrm{O}_{3}$ sample, HZSM-35 zeolite possesses a large percentage of strong Brönsted acids, which seem to be responsible for this severe deactivation.

\subsection{Discussion}

The aldol condensation reaction of formaldehyde and methyl acetate can be catalyzed by either bases or acids or both of them. In most of the published reports, attention was paid to catalysts with acid-base bifunctional properties, such as V-P-Si or alkaline metal oxide samples impregnated with other metals, owing to their better performance than pure acid or pure base catalysts. However, in this study, the Z-Cs-1wt sample, which possessed both acidity and alkalinity performed poorly with a lower yield of MA and AA than the pure $\mathrm{H}$-form of acidic zeolite. This result shows that alkalinity is not helpful, in fact it is harmful, for the aldol condensation reaction of DMM and MAc to produce MA and AA. This is inconsistent with published reports. To understand this discrepancy, we conducted the reaction over pure alkaline metal oxide catalysts, such as $\mathrm{Na}_{2} \mathrm{O}, \mathrm{K}_{2} \mathrm{O}$, and $\mathrm{Cs}_{2} \mathrm{O}$, and found that the DMM precursor does not decompose into formaldehyde over these alkaline sites. But DMM decomposes immediately into formaldehyde over acidic zeolite and enhances the aldol condensation reaction of DMM and MAc to produce MA and AA. This shows that acid sites are indispensable for the aldol condensation reaction of DMM and MAc. Here, it should be pointed out that this hypothesis is suitable only when DMM is used as the source for formaldehyde.

Strong acids and weak acids existed in the HZSM-35 as shown in the $\mathrm{NH}_{3}$-TPD results, with two desorption peaks of ammonia at different temperatures. After the addition of $1 \mathrm{wt} \%$ cesium, most of the acids in the HZSM-35, especially strong acids, are covered by base sites, followed by the disappearance of the initial period. In this period, a large quantity of hydrocarbon byproducts are formed because of the unavoidable methanol-to-olefin-like process at such high reaction temperatures. During the initial reaction period of the HZSM-35 zeolite, the strong acid sites might first catalyze the precursors to undergo a hydrogen transfer process, resulting in a large amount of hydrocarbon byproducts. Later, the remaining medium-strong and weak acids continue to catalyze the aldol condensation reaction. This suggests that not all the acidic sites of the zeolite participate in the aldol condensation reaction.

Medium-strong and weak acid sites seem to be the prime candidates for catalyzing the aldol condensation reaction of DMM and MAc to produce MA and AA without causing any drastic by-reactions. This hypothesis is validated by the considerably high activity and stability of the $\gamma-\mathrm{Al}_{2} \mathrm{O}_{3}$ sample in which weak acids exist predominantly along with a small number medium-strong acid sites. It seems that weak acids are powerful enough to catalyze the aldol condensation reaction.

\section{Conclusions}

Base sites are not helpful for catalyzing the aldol condensa- tion reaction of DMM and MAc to prepare acrylic acid and methyl acrylate because the DMM precursor does not decompose into formaldehyde over basic sites. Acid sites are indispensable for catalyzing the reaction when using DMM as the source of formaldehyde. However, not all acidic sites in the HZSM-35 zeolite are necessary for the reaction. Strong acids contribute mainly to an unavoidable methanol-to-olefin-like process, resulting in an initial period of the reaction during which a large amount of hydrocarbon byproducts are generated. Medium-strong acids and weak acids are optimal candidates for the aldol condensation reaction of DMM and MAc to produce acrylic acid and its ester without causing severe by-reactions. A good reaction performance with a considerably high activity and stability are obtained with the $\gamma-\mathrm{Al}_{2} \mathrm{O}_{3}$ sample, which possesses abundant weak acid sites with a few medium-strong acid sites. Further work on evaluating the maximum acidity and amount of acid for triggering the aldol condensation reaction is required.

\section{References}

[1] M. M. Bettahar, G. Costentin, L. Savary, J. C. Lavalley, Appl. Catal. A, 1996, 145, 1-48.

[2] W. Fang, Q. J. Ge, J. F. Yu, H. Y. Xu, Ind. Eng. Chem. Res., 2011, 50, 1962-1967.

[3] W. E. Campbell, E. L. McDaniel, W. H. Reece, J. E. Williams, H. S. Young, Ind. Eng. Chem. Prod. Res. Develop., 1970, 9, 325-334.

[4] A. X. Xu, Y. Wang, H. Q. Ge, S. Chen, Y. H. Li, W. M. Lu, Chin. J. Catal., 2013, 34, 2183-2191.

[5] W. Fang, Q. J. Ge, J. F. Yu, H. Y. Xu, Chin. J. Catal., 2011, 32, 1022-1026.

[6] P. Cheung, A. Bhan, G. J. Sunley, D. J. Law, E. Iglesia, J. Catal., 2007, 245, 110-123.

[7] J. L. Liu, H. F. Xue, X. M. Huang, P. H. Wu, S. J. Huang, S. B. Liu, W. J. Shen, Chin. J. Catal., 2010, 31, 729-738.

[8] M. Ai, Appl. Catal. A, 2005, 288, 211-215.

[9] B. Li, R. Y. Yan, L. Wang, Y.Y. Diao, Z. X. Li, S. J. Zhang, Ind. Eng. Chem. Res., 2014, 53, 1386-1394.

[10] B. Li, R. Y. Yan, L. Wang, Y. Y. Diao, Z. X. Li, S. J. Zhang, Catal. Lett., 2013, 143, 829-838.

[11] J. J. Spivey, M. R. Gogate, J. R. Zoeller, R. D. Colberg, Ind. Eng. Chem. Res., 1997, 36, 4600-4608.

[12] M. Ai, Appl. Catal., 1990, 63, 365-373.

[13] M. Ai, Bull. Chem. Soc. Jpn., 1990, 63, 3722-3724.

[14] M. Ai, Appl. Catal., 1989, 48, 51-61.

[15] M. Ai, Appl. Catal., 1989, 54, 29-36.

[16] M. Ai, J. Catal., 1988, 112, 194-200.

[17] M. Ai, J. Catal., 1987, 107, 201-208.

[18] M. R. Gogate, J. J. Spivey, J. R. Zoeller, Catal. Today, 1997, 36, 243-254.

[19] E. Dumitriu, V. Hulea, N. Bilba, G. Carja, A. Azzouz, J. Mol. Catal., 1993, 79, 175-185.

[20] R. Tanner, P. Gill, R. Wells, J. E. Bailie, G. Kelly, S. D. Jackson, G. J. Hutchings, Phys. Chem. Chem. Phys., 2002, 4, 688-695.

[21] M. Ai, J. Catal., 1987, 106, 273-279.

[22] J. Hu, Z. P. Lu, H. B. Yin, W. P. Xue, A. L. Wang, L. Q. Shen, S. X. Liu, J. Ind. Eng. Chem., 2016, 40, 145-151.

[23] D. Yang, D. Li, H. Y. Yao, G. L. Zhang, T. T. Jiao, Z. X. Li, C. S. Li, S. J. Zhang, Ind. Eng. Chem. Res., 2015, 54, 6865-6873.

[24] X. Z. Feng, B. Sun, Y. Yao, Q. Su, W. J. Ji, C. T. Au, J. Catal., 2014, 


\title{
Graphical Abstract
}

Chin. J. Catal., 2018, 39: 1129-1137 doi: 10.1016/S1872-2067(18)63069-4

One-step aldol condensation reaction of dimethoxymethane and methyl acetate over supported Cs/ZSM-35 zeolite catalysts

Zhanling Ma, Xiangang Ma, Hongchao Liu, Wenliang Zhu *, Xinwen Guo, Zhongmin Liu *

Dalian University of Technology;

Dalian Institute of Chemical Physics, Chinese Academy of Sciences;

University of Chinese Academy of Sciences

Acidity is indispensable for the aldol condensation reaction of DMM with MAc to prepare acrylic acid and its ester, whereas alkalinity is harmful.

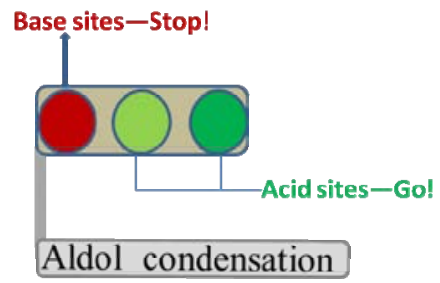

314, 132-141.

[25] Z. L. Ma, X. G. Ma, H. C. Liu, Y. L. He, W. L. Zhu, X. W. Guo, Z. M. Liu, Chem. Commun., 2017, 53, 9071-9074.

[26] X. S. Liu, R. E. Truitt, J. Am. Chem. Soc., 1997, 119, 9856-9860.

[27] C. Morterra, V. Bolis, G. Magnacca, Langmuir, 1994, 10, 1812-1824.

[28] Z. G. Zhu, H. Xu, J. G. Jiang, X. Liu, J. H. Ding, P. Wu, Appl. Catal. A,
2016, 519, 155-164.

[29] Z. G. Zhu, H. Xu, J. G. Jiang, Y. J. Guan, P. Wu, J. Catal., 2017, 352, 1-12.

[30] Z. C. Yang, Y. Q. Liu, J. C. Zhao, J. X. Gou, K. A. Sun, C. G. Liu, Chin. J. Catal., 2017, 38, 509-517.

[31] L. Z. Yang, Z. Y. Liu, Z. Liu, W. Y. Peng, Y. Q. Liu, C. G. Liu, Chin. J. Catal., 2017, 38, 683-690.

\section{Cs/ZSM-35 分子篮催化甲缩醛和乙酸甲酯发生一步法羟醛缩合反应}

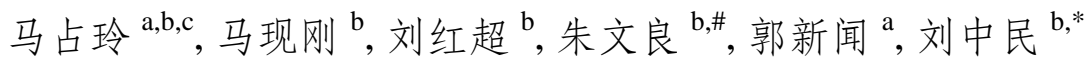 \\ a大连理工大学化工与环境生命学部化工学院精细化工国家重点实验室, 辽宁大连116024 \\ b中国科学院大连化学物理研究所甲醇制烯烃国家工程实验室, 辽宁大连 116023 \\ c中国科学院大学, 北京100049
}

摘要: 丙烯酸及其酯是重要的化工原料, 广泛应用于涂料、粘结剂、纤维等领域, 目前工业上常采用丙烯两段氧化法进行 制备. 然而该方法以石油基原料丙烯为源头, 采用 $\mathrm{V} / \mathrm{Mo} / \mathrm{Bi}$ 等金属催化剂, 不符合可持续发展理念, 且存在环境污染及氧 气下产物易过度氧化等问题. 因此, 如何高效、安全、大规模工业化制备丙烯酸及其酯是研究者追求的目标. 以乙酸甲酯 (MAc) 和甲醛为原料, 通过羟醛缩合一步制备丙烯酸及其酯是一条完全不同于丙烯氧化法的合成路径, 原料均可由煤基甲 醇得到, 符合我国“富煤、贫油、少气”的基本能源结构, 且该方法碳原子利用率为 100\%, 副产物仅为水, 属于绿色环保合成 路径.

羟醛缩合是典型的碳链增长反应, 可在酸性催化剂、碱性催化剂、以及酸碱双功能催化剂存在下发生. 碱性催化剂一 般为负载型碱金属氧化物, 例如以 $\mathrm{SiO}_{2}$ 为载体的负载型 $\mathrm{Na}, \mathrm{K}, \mathrm{Cs}$ 氧化物催化剂等, 但都存在活性组分流失的问题, 进而导 致催化剂的失活, 难以实现工业化. 酸碱双功能催化剂是目前研究的热点, 由于具有酸催化剂的高选择性和碱催化剂的高 活性, 其反应性能要远优于单一酸性催化剂和单一碱性催化剂, 广大研究者对此进行了深入广泛的研究, 目前基本处于实 验室阶段. 相对而言, 目前酸性催化剂上通过羟醛缩合反应制备丙烯酸及其酯的研究工作较少, 特别是以固体酸为催化剂 进行乙酸甲酯和甲醛气固相反应研究非常少见.

我们以甲缩醛为甲醛源, 创新性地采用固体硅铝分子篮为酸性催化剂, 催化甲缩醛 (DMM) 和 MAc 发生羟醛缩合反应 来制备丙烯酸. 硅铝分子篮具有较高的活性, 可高效地催化羟醛缩合反应, 且由于分子篮催化剂具有很好的再生性能, 即 使催化剂寿命较短, 也可采用流化床或移动床等反应器进行工业化, 因此存在良好的工业化前景. 为了进一步深入研究酸 性位和碱性位各自对 DMM 和 MAc 羟醛缩合反应的影响, 本文以 HZSM-35 分子篮为载体, 采用浸渍法制备不同碱金属铯 氧化物含量的催化剂, 利用氮气吸附/脱附方法和化学程序升温 $\left(\mathrm{NH}_{3}-\mathrm{TPD}\right)$ 方法对其孔结构和酸性质进行表征, 并进一步 
考察催化剂的性能. 结果表明, 微孔体积随着碱金属 Cs 负载量的增加而逐渐减小, 当 Cs 负载量增加至 $10 \mathrm{wt} \%$ 时, 样品微 孔体积从初始 $0.105 \mathrm{~cm}^{3} / \mathrm{g}$ 降至 $0.063 \mathrm{~cm}^{3} / \mathrm{g}$. $\mathrm{NH}_{3}$-TPD 结果显示, 当 $\mathrm{Cs}$ 负载量为 $1 \mathrm{wt} \%$, 酸性催化剂载体上的强酸和弱酸 活性位被大量碱性氧化物占据; 当负载量超过 $5 \mathrm{wt} \%$ 时, 所有的酸性位均被覆盖. 随后考察负载不同碱金属含量分子䇥的 羟醛缩合反应性能, 发现碱金属氧化物的引入不利于羟醛缩合反应的进行, 这主要是由于作为甲醛源的 DMM 只有在酸中 心上才能进行分解产生甲醛, 促使羟醛缩合反应顺利进行. 当采用 DMM 为甲醛源时, 体系中必须有酸性位存在. 同时得 知, 分子笁 HZSM-35 中强酸和弱酸均是羟醛缩合反应的有效酸性位, 但强酸同时催化原料发生类甲醇制烯烃过程, 致使大 量烃类副产物生成, 产生较重的积炭物种. 差醛缩合反应在含有大量弱酸催化剂上 $\left(\right.$ 如 $\left.\gamma-\mathrm{Al}_{2} \mathrm{O}_{3}\right)$ 也可顺利进行, 且具有较高 的活性和稳定性.

关键词: 羟醛缩合反应; 甲缩醛; 乙酸甲酯; 分子筛; 酸性

收稿日期: 2018-02-26. 接受日期: 2018-04-02. 出版日期: 2018-06-05.

*通讯联系人. 电话: (0411)84379998; 传真: (0411)84379038; 电子信箱: liuzm@dicp.ac.cn

通讯联系人. 电话: (0411)84379418; 传真: (0411)84379038; 电子信箱: wlzhu@dicp.ac.cn

本文的电子版全文由Elsevier出版社在ScienceDirect上出版(http://www.sciencedirect.com/science/journal/18722067). 